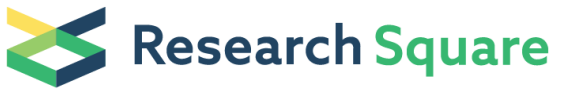 \\ Preprints are preliminary reports that have not undergone peer review. \\ They should not be considered conclusive, used to inform clinical practice, \\ or referenced by the media as validated information.
}

\section{Peri-prosthetic Bone Remodeling of Hydroxyapatite-coated Compaction Short Stem was Not Affected by Stem Alignment}

\section{Shinya Hayashi ( $\sim$ s11793290@yahoo.co.jp)}

Kobe University Graduate School of Medicine https://orcid.org/0000-0003-4308-9845

\section{Yuichi Kuroda}

Kobe University Graduate School of Medicine School of Medicine: Kobe Daigaku Daigakuin Igakukei Kenkyuka Igakubu

\section{Naoki Nakano}

Kobe University Graduate School of Medicine School of Medicine: Kobe Daigaku Daigakuin Igakukei Kenkyuka Igakubu

\section{Tomoyuki Matsumoto}

Kobe University Graduate School of Medicine School of Medicine: Kobe Daigaku Daigakuin Igakukei Kenkyuka Igakubu

\section{Tomoyuki Kamenaga}

Kobe University Graduate School of Medicine School of Medicine: Kobe Daigaku Daigakuin Igakukei Kenkyuka Igakubu

\section{Toshihisa Maeda}

Kobe University Graduate School of Medicine School of Medicine: Kobe Daigaku Daigakuin Igakukei Kenkyuka Igakubu

\section{Takahiro Niikura}

Kobe University Graduate School of Medicine School of Medicine: Kobe Daigaku Daigakuin Igakukei Kenkyuka Igakubu

\section{Ryosuke Kuroda}

Kobe University Graduate School of Medicine School of Medicine: Kobe Daigaku Daigakuin Igakukei Kenkyuka Igakubu

\section{Research article}

Keywords: total hip arthroplasty, short tapered-wedge stem, full hydroxyapatite-coated compaction short stem, bone mineral density, stem alignment

Posted Date: November 15th, 2021

DOI: https://doi.org/10.21203/rs.3.rs-1070995/v1

License: (c) (i) This work is licensed under a Creative Commons Attribution 4.0 International License. Read Full License

Version of Record: A version of this preprint was published at Journal of Orthopaedic Surgery and Research on March 3rd, 2022. See the published version at https://doi.org/10.1186/s13018-022-03022-7. 


\section{Abstract}

Background: We aimed to investigate the relationship between stem insertion alignment and postoperative bone mineral density (BMD) changes in patients with full hydroxyapatite-coated (HA) compaction short stem and short tapered-wedge stem.

Methods: This retrospective cohort study enrolled 115 consecutive patients (115 joints) undergoing total hip arthroplasty (THA) using the full HA compaction short $(n=59)$ and short tapered-wedge $(n=56)$ stems. Stem alignment including anteversion, valgus, and anterior tilt were measured by 3D-template using computed tomography (CT) data. Post-operative peri-prosthetic BMD was measured by dual-energy X-ray absorptiometry (DEXA). The relationship between stem alignment and BMD changes in the stems were analyzed.

Results: Both groups showed similar patterns of peri-prosthetic BMD changes. Stem insertion alignments of anteversion, valgus, and anterior tilt were different between the two types of stems. Stem alignment of valgus and anterior tilt did not affect peri-prosthetic BMD in either type of stem. An absolute anteversion difference between stem anteversion and original canal anteversion caused significant peri-prosthetic BMD loss in Gruen zones 1 and 7 in the tapered-wedge stem. However, stem alignment of absolute anteversion difference did not affect BMD changes in the HA compaction stem.

Conclusion: Peri-prosthetic bone remodeling remained unaffected by stem alignment after THA with the new short full HA compaction stem.

\section{Background}

Hydroxyapatite (HA) is widely used in THA to improve implant survivorship through accelerated early bone remodeling [1, 2]. This bioactive coating is believed to enhance the initial fixation by osseointegration [1, 2]. The ACTIS stem (DePuy Synthes, Warsaw, IN, USA) is a medial-collared, triple-tapered short stem with full HA-coating, and the cancellous bone was compacted without the implant in contact with the femoral cortex. The Tri-Lock bone preservation (BPS) stem (DePuy Synthes) is a short tapered-wedge stem which potentially preserves more bone stock, improving proximal load transfer and demonstrating lower stress shielding than long stems $[3,4]$.

Both the full HA-coated compaction short stem and short tapered-wedge stem were developed for minimally invasive THA and made from the same titanium alloy, but the geometry, type of surface coating, and concept of both stems differ substantially.

Recently, we reported that peri-prosthetic BMD changes was similar in full HA-coated compaction short stems and short tapered-wedge stems [5]. We further demonstrated that age, body mass index (BMI), and daily activity did not affect proximal femoral BMD changes in both types of stems, and femoral bone shape affected the BMD changes in the taperedwedge stem but not in the full HA compaction stem [5]. The contact force is dependent on subject-specific geometry and that specificity influences stress distribution in the peri-prosthetic bone after THA [6, 7]. A finite element method study reported that stress distribution in periprosthetic bone was dependent on stem alignment, especially anterior-posterior and varus-valgus alignments [8]. A radiographic study reported that varus alignment caused early stem loosening because of poor seating of the femoral prosthesis with decreased bone ingrowth [9]. The relation between varus-valgus alignment and stress distribution in the periprosthetic bone has been established well in biomechanical studies [9-13]. We have reported that excessive anteversion mismatch between anatomical canal and stem anteversions caused postoperative peri-prosthetic proximal BMD loss in a short tapered-wedge stem [14]. Thus, stress distribution in the peri-prosthetic bone was influenced not only by subject-specific geometry but also by stem alignment.

We hypothesized that stem alignment may affect different patterns of BMD change after THA between HA-coated compaction short stems and short tapered-wedge stems. Therefore, the aim of this study was to evaluate the relationship

Page 2/14 
between stem insertion alignment and postoperative BMD change in the full HA-coated compaction short stem and the short tapered-wedge stem.

\section{Methods}

\section{Patients' characteristics}

This retrospective cohort study enrolled 115 consecutive patients (115 joints) who underwent THA using the full HA compaction short stem (ACTIS; DePuy Synthes, Warsaw, IN; 59 joints) (Figure 1a) or the short tapered-wedge stem (Tri-Lock BPS; DePuy Synthes; 56 joints) (Figure 1b) at our institution between June 2016 and April 2017 (tapered-wedge) and April 2017 and July 2018 (full HA compaction). The preoperative diagnoses were osteoarthritis (grade 4 according to the Tönnis classification) (89 joints), avascular necrosis of the femoral head (22 joints), and rheumatoid arthritis (4 joints). Patients with a distorted anatomy of the proximal femur, osteoporosis (lumbar spine BMD $<0.8$ ), metabolic bone disease, and those who underwent bilateral THA were excluded.

All procedures were performed via the mini-anterolateral supine approach by a single senior surgeon. Full weight-bearing was allowed for all patients a day after the operation. BMI was assessed at the time of surgery. The postoperative follow-up included DEXA scanning and evaluation of clinical factors, including hip function, which was evaluated using two grading methods: (a) the Japanese Orthopaedic Association (JOA) score, which allocates 40 points for pain, 20 points for range of motion, 20 points for walking ability, and 20 points for activities of daily living, with a maximum total score of 100 points [15] and (b) the University of California Los Angeles (UCLA) activity score, which describes subjects' level of activity from 1 ("no physical activity, dependent on others") to 10 ("regular participation in impact sports"). The JOA and UCLA scores and radiographic findings were evaluated 2 years postoperatively.

\section{Measurement of stem alignment}

Pre-operative and postoperative CT scans from the pelvis to the knee joint were performed and transferred to a threedimensional template software (Zed Hip; Lexi, Tokyo, Japan). Computer-aided design models of the implants were manually adjusted for postoperative multiplanar reconstruction in the CT images (Figure 2). Stem anteversion and anatomical canal anteversion angles were measured with respect to the posterior condylar line axis of the femur [16]. We compared the anatomical canal anteversion and postoperative stem anteversion, and the anteversion error was defined as the difference between the stem anteversion and anatomical canal anteversion. Patients were divided into two groups. The outliers of stem anteversion were defined as having an absolute difference of $5^{\circ}$ or more between anatomical canal anteversion and postoperative stem anteversion, and the outliers of varus-valgus and anterior-posterior tilt angle were defined as having an absolute difference of $3^{\circ}$ or more according to previous studies $[14,17]$.

\section{DEXA measurements}

DEXA scanning was performed using a DPX-L scanner (GE Lunar Corporation, Madison, WI, USA). DPX-L total body scans were performed using the software version 1.35 , which set the appropriate transverse speed at $16 \mathrm{~cm} / \mathrm{s}, 8 \mathrm{~cm} / \mathrm{s}$, or $4 \mathrm{~cm} / \mathrm{s}$ depending on the subject's height. Patients were positioned supine with their legs in the neutral position and a knee and foot support to facilitate the scanning of the anterior-posterior projection of the proximal femur, including the area distal to the prosthesis, using an edge-detection technique.

Peri-prosthetic BMD was determined postoperatively in seven regions of interest (ROIs) based on the Gruen zones [18]. The seven Gruen zones were positioned based on the distal tip and shoulder of the prosthesis. The two most proximal Gruen zones ( 1 and 7) were also combined to create a proximal femur ROI, which represents the region where the porous coating of the uncemented stems is normally situated. The values were expressed as area BMD in grams per square centimeter. The 
BMD around the stem was assessed within 1 month (baseline BMD) and 6, 12, 18, and 24 months postoperatively by a technician in the radiology department who was blinded to the stem used. BMD ratios were calculated by dividing each BMD value at $6,12,18$, and 24 months postoperatively by the baseline BMD.

\section{Statistical analysis}

All data are expressed as mean \pm standard deviation (SD) unless otherwise indicated. The differences in patients' backgrounds and stem alignment between the full HA compaction and tapered-wedge groups were analyzed using the Mann-Whitney $U$ test (Table 1). Sequential changes in BMD within each group were analyzed by one-way analysis of variance using Tukey's post-hoc test. Additionally, the BMD at each timepoint was compared between the groups using the Mann-Whitney U test (Figure 2). The differences in peri-prosthetic BMD changes for stem valgus, anterior tilt, and absolute anteversion error alignment between outliers and non-outliers were analyzed using the Mann-Whitney U test (Tables 2, 3, 4). Statistical significance was set at $p<0.05$.

Post-hoc power analysis was performed using G*Power [19]. For comparison between groups, for a sample size of 59 versus 56 elements in two groups and a type-l error (a) of 0.05 , the study is expected to provide a power (1- $\beta$ ) of 0.83 for detecting an effect size of 0.5 . Comparing the outliers and non-outliers, we calculated the effect size by means and SDs based on Cohen's $d$ for each parameter and the 95\% confidence interval for effect sizes (Table 2, 3, 4) [20]

\section{Results}

\section{Patients' characteristics}

We divided the patients into two groups: the full HA compaction short stem and the tapered-wedge stem groups. The mean patient age at operation was $66.8 \pm 11.1$ years in the full HA compaction group, and $67.5 \pm 9.1$ years in the tapered-wedge group ( $p=0.800$ ). At clinical evaluation performed 24 months postoperatively, the mean BMI was $22.8 \pm 2.9 \mathrm{~kg} / \mathrm{m}^{2}$ in the full HA compaction group and $23.7 \pm 3.7 \mathrm{~kg} / \mathrm{m}^{2}$ in the tapered-wedge group $(\mathrm{p}=0.843)$. The JOA score was $96.1 \pm 4.5$ in the full HA compaction group and $95.9 \pm 6.2$ in the tapered-wedge group $(p=0.825)$. The UCLA score was $6.4 \pm 1.6$ in the full HA compaction group and $6.1 \pm 1.5$ in the tapered-wedge group $(p=0.268)$. The mean values for age, BMI, JOA score, and UCLA activity score were not significantly different between the groups.

\section{Stem insertion alignment was affected by stem design}

Table 2 demonstrates that no significant differences in stem anteversion and canal anteversion were found between the HA compaction and tapered-wedge groups. The mean absolute value of surgical error (postoperative stem anteversion-canal anteversion) was $5.2^{\circ} \pm 4.8^{\circ}$ (HA compaction) and $8.8^{\circ} \pm 9.1^{\circ}$ (tapered-wedge), and the mean absolute value of anteversion error was significantly higher in the tapered-wedge group than in the HA compaction group $(p=0.039)$ (Table 1). The mean absolute values of valgus error were $3.1^{\circ} \pm 2.2^{\circ}$ (HA compaction) and $1.8^{\circ} \pm 1.8^{\circ}$ (tapered-wedge), and the error was significantly higher in the HA compaction group than in the tapered-wedge group $(p<0.001)$ (Table 1). The mean absolute values of anterior tilt error were $6.0^{\circ} \pm 2.2^{\circ}$ (HA compaction) and $3.1^{\circ} \pm 2.1^{\circ}$ (tapered-wedge), and the error was significantly higher in the HA compaction group than in the tapered-wedge group $(p<0.001)$ (Table 1).

\section{Peri-prosthetic BMD changes were similar between the groups}

Minimal BMD changes were found in the distal femur (Gruen zones 3, 4, and 5) and zone 6 in both types of stems (Figure 3). However, a significant BMD loss was observed in zones 1 and 7 at each timepoint in both groups compared with the BMD value obtained within 1 month postoperatively (full HA compaction: zone 1, 24 months, p<0.001; zone 7, 24 months, 
$p<0.001$ ) (tapered-wedge: zone 1, 24 months, $p<0.001$; zone 7, 24 months, $p<0.001$ ). On comparing the BMD changes between the groups, we found that the change in BMD of the tapered-wedge stem group was significantly higher in zone 2 at each timepoint. The change in BMD of the full HA compaction group was significantly higher in zone 4 (Figure 3).

\section{Stem alignment affected peri-prosthetic BMD loss in tapered-wedge stem but not in HA compaction stem}

Table 2 demonstrates that larger valgus alignment caused significant differences in peri-prosthetic BMD loss in Gruen zones 2 in the tapered-wedge group, but alignment did not affect BMD changes in the HA compaction group. Tables 2 and 3 demonstrate that peri-prosthetic BMD did not change between the outlier and non-outlier groups of anterior tilt in both HA compaction and tapered-wedge stems. Table 4 demonstrates that larger absolute anteversion errors caused significant differences in peri-prosthetic BMD loss in Gruen zones 1 and 7 in the tapered-wedge group. However, stem alignment of absolute anteversion error did not affect BMD changes in the HA compaction group (Table 4).

\section{HA compaction stem and tapered-wedge stem represent different patterns of contact to bone surface}

Figure 4a demonstrates the subject-specific differences of representative cases in HA compaction and tapered-wedge stems. In the HA compaction stem, the stem was in contact with the anterior wall, posterior edge of the proximal femur, and distal anterior wall in the sagittal view and widely occupied the antero-posterior area of the proximal femur in the axial view. Meanwhile, in the tapered-wedge stem, the stem contacts only the posterior edge of the proximal femur in the sagittal view and less occupied antero-posterior area of the proximal femur in the axial view (Figure 4b).

\section{Discussion}

In this study, we observed similar patterns of peri-prosthetic BMD changes in the full HA compaction short stem and taperedwedge stem, although stem alignments of anteversion, valgus, and anterior tilt were different between the two groups. Furthermore, the stem alignment of the tapered-wedge stem affects peri-prosthetic BMD loss after THA, but that of the HA compaction stem did not.

Taniguchi et al. compared the stem insertion alignment of metaphyseal filling and short tapered-wedge stems and found that tapered-wedge stems had greater variation in the increase in anteversion than metaphyseal filling stems [21]. Our previous report demonstrated that the insertion alignment of short tapered-wedge stems was similar to that of straight stems during mini-invasive THA [22]. The current study demonstrated that the alignments of anteversion, valgus, and anterior tilt were different between HA compaction and tapered-wedge stems. This difference can be explained by stem geometry. The current study demonstrated that the HA compaction stem was in contact with the anterior wall, the posterior edge of the proximal femur, and the distal anterior wall in the sagittal view and widely occupied the antero-posterior area of the proximal femur in the axial view. The contact pattern indicates that sagittal stem alignment is fixed at three points and changing anteversion and sagittal stem alignment is not easy. Therefore, HA compaction short stems may cause larger anterior tilt and smaller anteversion errors. Another feature of the HA compaction short stem is the medial collar. In several cases, the medial collar may soon attach to the calcar region, and the stem alignment changes to valgus during bone compaction.

Our current study showed findings similar to those of a previous report; excessive mismatch of stem anteversion and anatomical canal anteversion caused peri-prosthetic proximal BMD loss in short tapered-wedge stems [14]. However, stem insertion alignment did not affect the BMD changes in the HA compaction stem group. Kim et al. reported that the metaphyseal fitting stem, which was particularly characterized by metaphyseal fixation, predominantly indicated proximal 
load transfer and excellent peri-prosthetic BMD preservation in the proximal region of the stem [23]. The proximal profile of the HA compaction short stem represents a thicker antero-posterior width than the short tapered-wedge stem and can be expected to be fixed in the proximal femoral cavity and provide rotational stability in addition to the effect of HA-coating for early bone remodeling.

The limitations of this study were as follows: First, this was not a randomized study but a retrospective cohort study. To evaluate the clinical and radiographic outcomes, an analysis of a randomized selection of patients is preferable. The backgrounds of the patients were similar in our study. Secondly, the sample size, with respect to the evaluation of outcomes, was small. In particular, the sample size for the comparison between outliers and non-outliers was underpowered for analysis. Finally, the preoperative peri-prosthetic BMD was not measured. We did not compare BMD values pre- and postoperatively.

\section{Conclusions}

In our study, similar patterns of peri-prosthetic BMD changes were observed between the full HA compaction short stem and tapered-wedge stem. Stem insertion alignments of anteversion, valgus, and anterior tilt were different between the two types of stem groups because of the different stem geometries. Moreover, stem alignment of the tapered-wedge stem affects periprosthetic BMD loss after THA, but HA compaction stem did not due to wide occupation of the proximal femoral cavity.

\section{Abbreviations}

BMD, Bone mineral density

BMI, Body mass index

BPS, Bone preservation

CT, Computed tomography

DEXA, Dual-energy $\mathrm{X}$-ray absorptiometry

HA, Hydroxyapatite-coated

JOA, Japanese Orthopaedic Association

ROI, Regions of interest

SD, Standard deviation

THA, Total hip arthroplasty

UCLA, University of California Los Angeles

\section{Declarations}

\section{Ethics approval and consent to participate}

The study protocol was approved by the Institutional Review Board on September 8, 2011 (No. 1220), and patients provided informed consent for participation.

\section{Consent for publication}




\section{Availability of data and materials}

All data generated or analyzed during this study are included in this published article.

\section{Competing interests}

The authors declare that they have no competing interests.

\section{Funding}

No funding was received for this study.

\section{Author contributions}

SHay participated in the study design, drafting of the manuscript, and data collection. YK carried out data collection and drafting of the manuscript. NN participated in the data collection and drafting of the manuscript. TM participated in the study design and helped to revised the manuscript. TK participated in the data collection and drafting of the manuscript. TM carried out data collection and drafting of the manuscript. TN participated in the data collection and drafting of the manuscript. RK participated in the study design and helped to revised the manuscript. All authors read and approved the final manuscript.

\section{Acknowledgements}

Not applicable

\section{References}

1. Chen Y-L, Lin T, Liu A, Shi M-M, Hu B, Shi Z-L, et al. Does hydroxyapatite coating have no advantage over porous coating in primary total hip arthroplasty? A meta-analysis. Journal of orthopaedic surgery and research. 2015;10:21.

2. Vidalain JP. Twenty-year results of the cementless Corail stem. International Orthopaedics. 2011;35(2):189-94.

3. Molli RG, Lombardi AV, Jr., Berend KR, Adams JB, Sneller MA. A short tapered stem reduces intraoperative complications in primary total hip arthroplasty. Clinical orthopaedics and related research. 2012;470(2):450-61.

4. Patel RM, Smith MC, Woodward CC, Stulberg SD. Stable fixation of short-stem femoral implants in patients 70 years and older. Clinical orthopaedics and related research. 2012;470(2):442-9.

5. Hayashi S, Hashimoto S, Kuroda Y, Nakano N, Matsumoto T, Kamenaga T, et al. Hydroxyapatite-coated compaction short stem represents a characteristic pattern of peri-prosthetic bone remodelling after total hip arthroplasty. Arch Orthop Trauma Surg. 2021.

6. Jonkers I, Sauwen N, Lenaerts G, Mulier M, Van der Perre G, Jaecques S. Relation between subject-specific hip joint loading, stress distribution in the proximal femur and bone mineral density changes after total hip replacement. Journal of biomechanics. 2008;41(16):3405-13.

7. Lenaerts G, De Groote F, Demeulenaere B, Mulier M, Van der Perre G, Spaepen A, et al. Subject-specific hip geometry affects predicted hip joint contact forces during gait. Journal of biomechanics. 2008;41(6):1243-52. 
8. Bah MT, Nair PB, Taylor M, Browne M. Efficient computational method for assessing the effects of implant positioning in cementless total hip replacements. Journal of biomechanics. 2011;44(7):1417-22.

9. Vresilovic EJ, Hozack WJ, Rothman RH. Radiographic assessment of cementless femoral components. Correlation with intraoperative mechanical stability. The Journal of arthroplasty. 1994;9(2):137-41.

10. Anglin C, Masri BA, Tonetti J, Hodgson AJ, Greidanus NV. Hip resurfacing femoral neck fracture influenced by valgus placement. Clinical orthopaedics and related research. 2007;465:71-9.

11. Davis ET, Olsen M, Zdero R, Waddell JP, Schemitsch EH. Femoral neck fracture following hip resurfacing: the effect of alignment of the femoral component. The Journal of bone and joint surgery British volume. 2008;90(11):1522-7.

12. Nabavi A, Yeoh KM, Shidiac L, Appleyard R, Gillies RM, Turnbull A. Effects of positioning and notching of resurfaced femurs on femoral neck strength: a biomechanical test. J Orthop Surg (Hong Kong). 2009;17(1):47-50.

13. Radcliffe IA, Taylor M. Investigation into the effect of varus-valgus orientation on load transfer in the resurfaced femoral head: a multi-femur finite element analysis. Clinical biomechanics. 2007;22(7):780-6.

14. Hayashi S, Hashimoto S, Matsumoto T, Takayama K, Nishida K, Ishida K, et al. Stem anteversion mismatch to the anatomical anteversion causes loss of periprosthetic bone density after THA. J Orthop Surg (Hong Kong). 2017;25(3):2309499017739478.

15. Hasegawa Y, Iwata H, Mizuno M, Genda E, Sato S, Miura T. The natural course of osteoarthritis of the hip due to subluxation or acetabular dysplasia. Arch Orthop Trauma Surg. 1992;111(4):187-91.

16. Dorr LD, Wan Z, Malik A, Zhu J, Dastane M, Deshmane P. A comparison of surgeon estimation and computed tomographic measurement of femoral component anteversion in cementless total hip arthroplasty. J Bone Joint Surg Am. 2009;91(11):2598-604.

17. Vresilovic EJ, Hozack WJ, Rothman RH. Radiographic assessment of cementless femoral components. Correlation with intraoperative mechanical stability. J Arthroplasty. 1994;9(2):137-41.

18. Gruen TA, McNeice GM, Amstutz HC. "Modes of failure" of cemented stem-type femoral components: a radiographic analysis of loosening. Clinical orthopaedics and related research. 1979(141):17-27.

19. Faul F, Erdfelder E, Buchner A, Lang AG. Statistical power analyses using G*Power 3.1: tests for correlation and regression analyses. Behav Res Methods. 2009;41(4):1149-60.

20. Durlak JA. How to Select, Calculate, and Interpret Effect Sizes. Journal of Pediatric Psychology. 2009;34(9):917-28.

21. Taniguchi N, Jinno T, Koga D, Hagino T, Okawa A, Haro H. Cementless Hip Stem Anteversion in the Dysplastic Hip: A Comparison of Tapered Wedge vs Metaphyseal Filling. J Arthroplasty. 2017;32(5):1547-52.

22. Hayashi S, Fujishiro T, Hashimoto S, Kanzaki N, Kuroda R, Kurosaka M. The contributing factors of tapered wedge stem alignment during mini-invasive total hip arthroplasty. J Orthop Surg Res. 2015;10:52.

23. Kim YH, Choi Y, Kim JS. Comparison of bone mineral density changes around short, metaphyseal-fitting, and conventional cementless anatomical femoral components. J Arthroplasty. 2011;26(6):931-40 e1.

\section{Tables}

Table 1

Stem alignment 


\begin{tabular}{|llll|}
\hline & Full HA compaction & Tapered wedge & p-value \\
\hline stem anteversion & $33.7 \pm 11.6$ & $32.1 \pm 10.5$ & 0.538 \\
\hline valgus & $3.1 \pm 2.2$ & $1.8 \pm 1.8$ & $<0.001$ \\
\hline anterior tilt & $6.0 \pm 2.2$ & $3.1 \pm 2.1$ & $<0.001$ \\
\hline canal anteversion & $33.3 \pm 12.8$ & $29.1 \pm 11.1$ & 0.101 \\
\hline anteversion error & $0.4 \pm 7.1$ & $3.0 \pm 10.5$ & $<0.001$ \\
\hline absolute anteversion error & $5.2 \pm 4.8$ & $8.8 \pm 9.1$ & 0.039 \\
\hline
\end{tabular}

Table 2

Relation between stem valgus alignment and BMD change at 24 months post-operatively in the Gruen zones

\begin{tabular}{|c|c|c|c|c|c|c|c|c|c|c|}
\hline \multicolumn{11}{|c|}{ Outlier vs Non-outlier (valgus alignment) } \\
\hline & \multicolumn{5}{|c|}{ HA full compaction } & \multicolumn{5}{|c|}{ Tapered wedge } \\
\hline & $\begin{array}{l}\text { Outlier } \\
(n=27)\end{array}$ & $\begin{array}{l}\text { Non- } \\
\text { outlier }\end{array}$ & $\begin{array}{l}P \\
\text { value }\end{array}$ & $\begin{array}{l}\text { Effect } \\
\text { size }\end{array}$ & $\begin{array}{l}95 \% \\
\mathrm{Cl}\end{array}$ & $\begin{array}{l}\text { Outlier } \\
(n=9)\end{array}$ & $\begin{array}{l}\text { Non- } \\
\text { outlier }\end{array}$ & $\begin{array}{l}P \\
\text { value }\end{array}$ & $\begin{array}{l}\text { Effect } \\
\text { size }\end{array}$ & $\begin{array}{l}95 \% \\
\mathrm{Cl}\end{array}$ \\
\hline & & $(n=32)$ & & $\begin{array}{l}\text { (Cohen's } \\
\text { d) }\end{array}$ & & & $(n=47)$ & & $\begin{array}{l}\text { (Cohen's } \\
\text { d) }\end{array}$ & \\
\hline Zone1 & $0.90 \pm 0.17$ & $0.92 \pm 0.09$ & 0.141 & 0.15 & $\begin{array}{l}-0.36 \\
-0.66\end{array}$ & $0.92 \pm 0.12$ & $0.90 \pm 0.14$ & 0.315 & -0.15 & $\begin{array}{l}-0.86 \\
- \\
0.57\end{array}$ \\
\hline Zone2 & $0.92 \pm 0.14$ & $0.90 \pm 0.09$ & 0.159 & -0.17 & $\begin{array}{l}-0.69 \\
-0.34\end{array}$ & $0.90 \pm 0.18$ & $1.00 \pm 0.10$ & $0.014^{\star}$ & 0.87 & $\begin{array}{l}0.14 \\
- \\
1.60\end{array}$ \\
\hline Zone3 & $1.02 \pm 0.07$ & $1.00 \pm 0.03$ & 0.084 & -0.38 & $\begin{array}{l}-0.9- \\
0.134\end{array}$ & $1.01 \pm 0.13$ & $1.02 \pm 0.18$ & 0.805 & 0.06 & $\begin{array}{l}-0.66 \\
- \\
0.77\end{array}$ \\
\hline Zone4 & $1.04 \pm 0.07$ & $1.04 \pm 0.04$ & 0.382 & 0.00 & $\begin{array}{l}-0.51 \\
-0.51\end{array}$ & $1.05 \pm 0.06$ & $1.01 \pm 0.05$ & 0.054 & -0.78 & $\begin{array}{l}-1.5- \\
-0.05\end{array}$ \\
\hline Zone5 & $1.05 \pm 0.10$ & $1.03 \pm 0.03$ & 0.505 & -0.28 & $\begin{array}{l}-0.80 \\
-0.23\end{array}$ & $1.02 \pm 0.16$ & $1.05 \pm 0.12$ & 0.825 & 0.24 & $\begin{array}{l}-0.48 \\
- \\
0.95\end{array}$ \\
\hline Zone6 & $0.93 \pm 0.15$ & $0.98 \pm 0.14$ & 0.421 & 0.35 & $\begin{array}{l}-0.17 \\
-0.86\end{array}$ & $0.97 \pm 0.15$ & $1.01 \pm 0.13$ & 0.594 & 0.30 & $\begin{array}{l}-0.42 \\
- \\
1.02\end{array}$ \\
\hline Zone7 & $0.82 \pm 0.16$ & $0.81 \pm 0.24$ & 0.979 & -0.05 & $\begin{array}{l}-0.56 \\
-0.46\end{array}$ & $0.84 \pm 0.19$ & $0.83 \pm 0.15$ & 0.948 & -0.06 & $\begin{array}{l}-0.78 \\
- \\
0.65\end{array}$ \\
\hline
\end{tabular}

Table 3

Relation between stem anterior tilt alignment and BMD change at 24 months post-operatively in the Gruen zones 
Outlier vs Non-outlier (anterior tilt)

\begin{tabular}{|c|c|c|c|c|c|c|c|c|c|c|}
\hline & \multicolumn{5}{|c|}{ HA full compaction } & \multicolumn{5}{|c|}{ Tapered wedge } \\
\hline & $\begin{array}{l}\text { Outlier } \\
(\mathrm{n}=48)\end{array}$ & $\begin{array}{l}\text { Non- } \\
\text { outlier } \\
(n=11)\end{array}$ & $\begin{array}{l}P \\
\text { value }\end{array}$ & $\begin{array}{l}\text { Effect } \\
\text { size } \\
\text { (Cohen's } \\
\text { d) }\end{array}$ & $95 \% \mathrm{Cl}$ & $\begin{array}{l}\text { Outlier } \\
(\mathrm{n}=24)\end{array}$ & $\begin{array}{l}\text { Non- } \\
\text { outlier } \\
(n=32)\end{array}$ & $\begin{array}{l}\mathrm{P} \\
\text { value }\end{array}$ & $\begin{array}{l}\text { Effect } \\
\text { size } \\
\text { (Cohen's } \\
\text { d) }\end{array}$ & $\begin{array}{l}95 \% \\
\mathrm{Cl}\end{array}$ \\
\hline Zone1 & $0.91 \pm 0.14$ & $0.87 \pm 0.15$ & 0.261 & -0.28 & $\begin{array}{l}-0.94- \\
0.38\end{array}$ & $0.88 \pm 0.10$ & $0.95 \pm 0.13$ & 0.055 & 0.59 & $\begin{array}{l}0.05 \\
- \\
1.13\end{array}$ \\
\hline Zone2 & $0.91 \pm 0.12$ & $0.89 \pm 0.08$ & 0.492 & -0.18 & $\begin{array}{l}-0.83- \\
0.48\end{array}$ & $0.98 \pm 0.13$ & $1.00 \pm 0.11$ & 0.845 & 0.17 & $\begin{array}{l}-0.36 \\
- \\
0.70\end{array}$ \\
\hline Zone3 & $1.01 \pm 0.06$ & $0.99 \pm 0.03$ & 0.249 & -0.36 & $\begin{array}{l}-1.02- \\
0.30\end{array}$ & $1.02 \pm 0.10$ & $1.05 \pm 0.08$ & 0.532 & 0.34 & $\begin{array}{l}-0.20 \\
- \\
0.87\end{array}$ \\
\hline Zone4 & $1.04 \pm 0.06$ & $1.03 \pm 0.06$ & 0.799 & -0.17 & $\begin{array}{l}-0.82- \\
0.49\end{array}$ & $1.02 \pm 0.05$ & $1.01 \pm 0.05$ & 0.769 & -0.30 & $\begin{array}{l}-0.83 \\
- \\
0.23\end{array}$ \\
\hline Zone5 & $1.04 \pm 0.09$ & $1.02 \pm 0.04$ & 0.638 & -0.24 & $\begin{array}{l}-0.90- \\
0.42\end{array}$ & $1.06 \pm 0.14$ & $1.03 \pm 0.11$ & 0.434 & -0.24 & $\begin{array}{l}-0.77 \\
- \\
0.29\end{array}$ \\
\hline Zone6 & $0.95 \pm 0.15$ & $0.98 \pm 0.07$ & 0.904 & 0.22 & $\begin{array}{l}-0.44- \\
0.87\end{array}$ & $1.00 \pm 0.13$ & $1.01 \pm 0.14$ & 0.984 & 0.07 & $\begin{array}{l}-0.46 \\
- \\
0.60\end{array}$ \\
\hline Zone7 & $0.81 \pm 0.21$ & $0.84 \pm 0.13$ & 0.638 & 0.15 & $\begin{array}{l}-0.50- \\
0.81\end{array}$ & $0.84 \pm 0.15$ & $0.83 \pm 0.16$ & 0.784 & -0.06 & $\begin{array}{l}-0.59 \\
- \\
0.47\end{array}$ \\
\hline
\end{tabular}

Cl; confidence interval

Table 4

Relation between stem absolute anteversion error and BMD change at 24 months post-operatively in the Gruen zones 


\begin{tabular}{|c|c|c|c|c|c|c|c|c|c|c|}
\hline \multicolumn{11}{|c|}{ Outlier vs Non-outlier (absolute anteversion error) } \\
\hline & \multicolumn{5}{|c|}{ HA full compaction } & \multicolumn{5}{|c|}{ Tapered wedge } \\
\hline & $\begin{array}{l}\text { Outlier } \\
(\mathrm{n}=24)\end{array}$ & $\begin{array}{l}\text { Non- } \\
\text { outlier }\end{array}$ & $\begin{array}{l}\mathrm{P} \\
\text { value }\end{array}$ & $\begin{array}{l}\text { Effect } \\
\text { size }\end{array}$ & $\begin{array}{l}95 \% \\
\mathrm{Cl}\end{array}$ & $\begin{array}{l}\text { Outlier } \\
(\mathrm{n}=28)\end{array}$ & $\begin{array}{l}\text { Non- } \\
\text { outlier }\end{array}$ & $\begin{array}{l}\mathrm{P} \\
\text { value }\end{array}$ & $\begin{array}{l}\text { Effect } \\
\text { size }\end{array}$ & $\begin{array}{l}95 \% \\
\mathrm{Cl}\end{array}$ \\
\hline & & $(n=35)$ & & $\begin{array}{l}\text { (Cohen's } \\
\text { d) }\end{array}$ & & & $(n=28)$ & & $\begin{array}{l}\text { (Cohen's } \\
\text { d) }\end{array}$ & \\
\hline Zone1 & $0.92 \pm 0.11$ & $0.90 \pm 0.16$ & 0.287 & -0.14 & $\begin{array}{l}-0.67 \\
-0.39\end{array}$ & $0.89 \pm 0.11$ & $0.96 \pm 0.11$ & $0.022^{*}$ & 0.64 & $\begin{array}{l}0.10 \\
- \\
1.17\end{array}$ \\
\hline Zone2 & $0.92 \pm 0.12$ & $0.90 \pm 0.11$ & 0.369 & -0.18 & $\begin{array}{l}-0.71 \\
-0.36\end{array}$ & $0.98 \pm 0.10$ & $1.00 \pm 0.14$ & 0.249 & 0.16 & $\begin{array}{l}-0.36 \\
- \\
0.69\end{array}$ \\
\hline Zone3 & $1.01 \pm 0.05$ & $1.02 \pm 0.06$ & 0.937 & 0.18 & $\begin{array}{l}-0.34 \\
-0.70\end{array}$ & $1.03 \pm 0.08$ & $1.04 \pm 0.10$ & 0.571 & 0.11 & $\begin{array}{l}-0.41 \\
- \\
0.64\end{array}$ \\
\hline Zone4 & $1.03 \pm 0.04$ & $1.05 \pm 0.06$ & 0.267 & 0.38 & $\begin{array}{l}-0.15 \\
-0.90\end{array}$ & $1.01 \pm 0.05$ & $1.02 \pm 0.05$ & 0.265 & 0.20 & $\begin{array}{l}-0.33 \\
- \\
0.73\end{array}$ \\
\hline$\underline{\text { Zone5 }}$ & $1.01 \pm 0.07$ & $1.06 \pm 0.09$ & 0.105 & 0.61 & $\begin{array}{l}0.08- \\
1.14\end{array}$ & $1.04 \pm 0.16$ & $1.05 \pm 0.14$ & 0.653 & 0.07 & $\begin{array}{l}-0.46 \\
- \\
0.59\end{array}$ \\
\hline Zone6 & $0.95 \pm 0.15$ & $0.96 \pm 0.14$ & 0.275 & 0.07 & $\begin{array}{l}-0.45 \\
-0.60\end{array}$ & $0.98 \pm 0.11$ & $1.04 \pm 0.16$ & 0.154 & 0.44 & $\begin{array}{l}-0.09 \\
- \\
0.97\end{array}$ \\
\hline Zone7 & $0.82 \pm 0.22$ & $0.81 \pm 0.19$ & 0.930 & -0.05 & $\begin{array}{l}-0.57 \\
-0.47\end{array}$ & $0.79 \pm 0.13$ & $0.89 \pm 0.17$ & $0.048^{*}$ & 0.66 & $\begin{array}{l}0.12 \\
- \\
1.20\end{array}$ \\
\hline
\end{tabular}

\section{Figures}


Figure 1

(a)

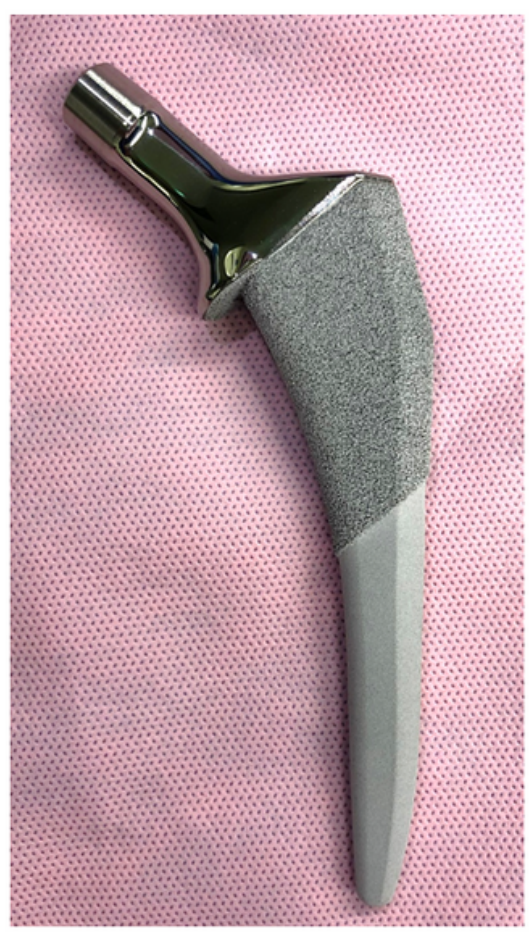

(b)

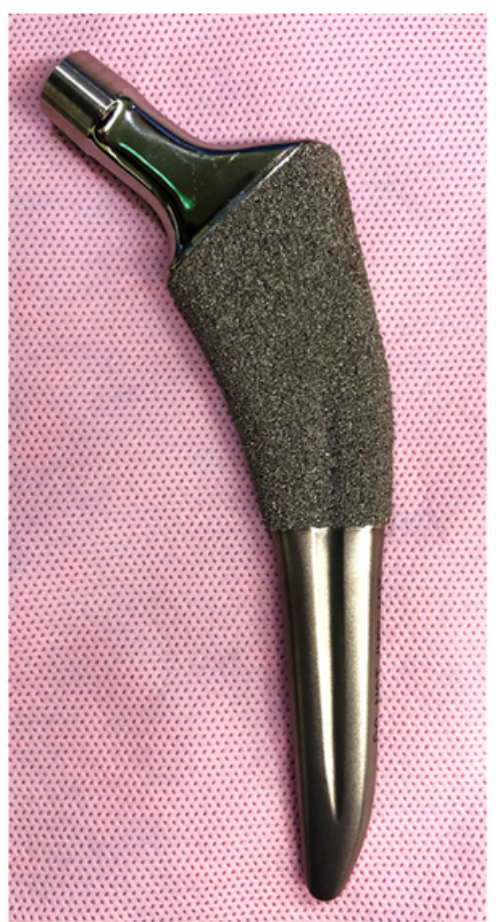

Figure 1

Images of (a) the full HA compaction short stem (ACTIS) and (b) the short tapered-wedge stem (Tri-Lock BPS).

Figure 2

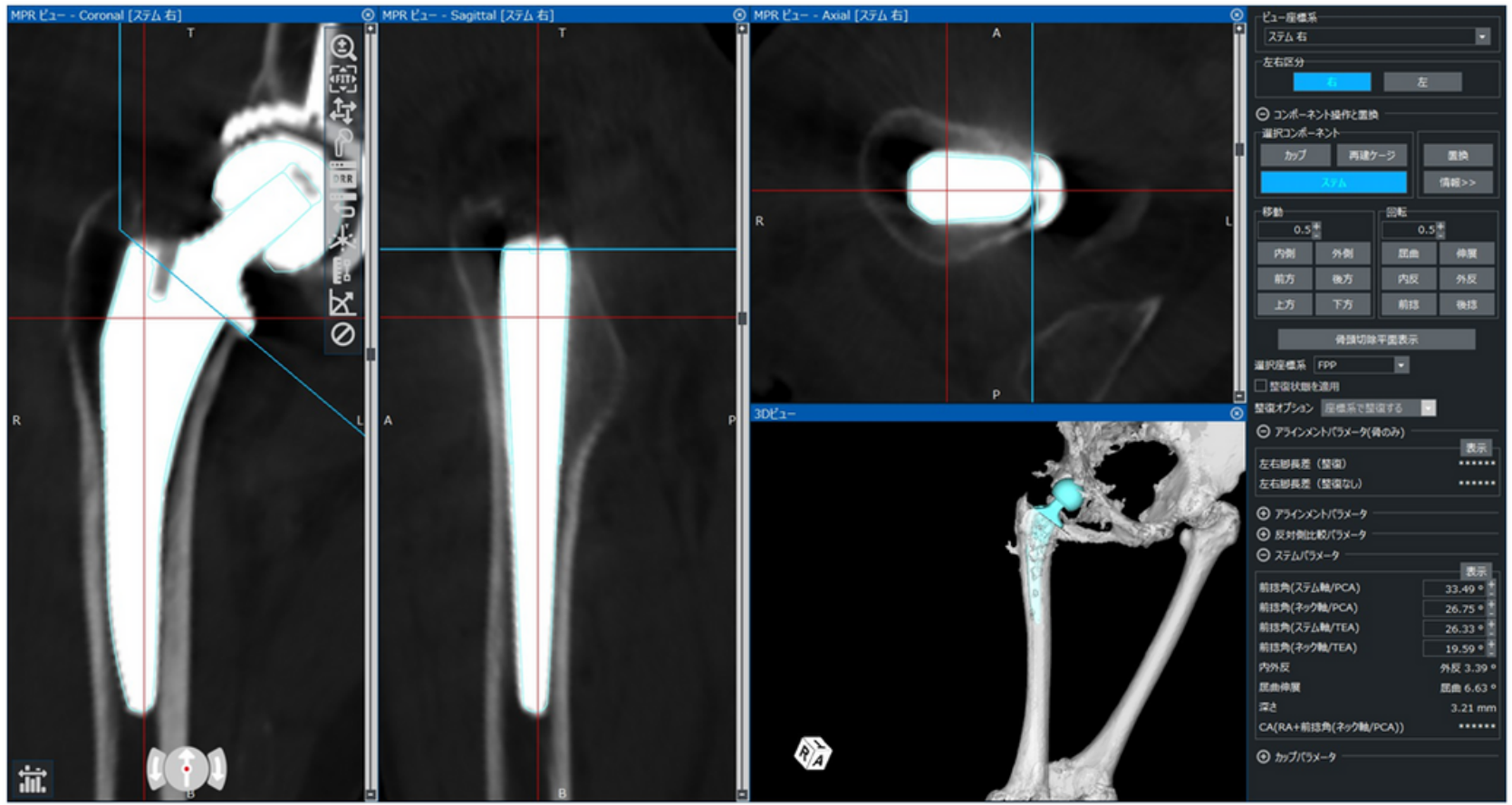

Figure 2 
Stem alignments are measured by superimposing the templates of the stem data on postoperative images of the femoral component using Zed Hip software.

Figure 3

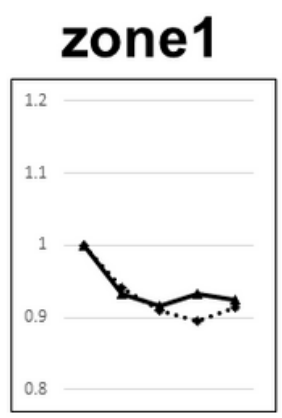

zone5

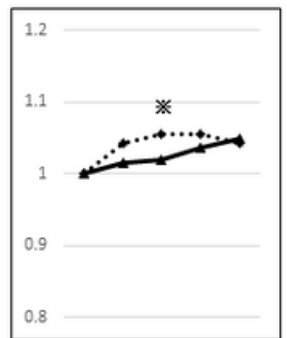

zone2

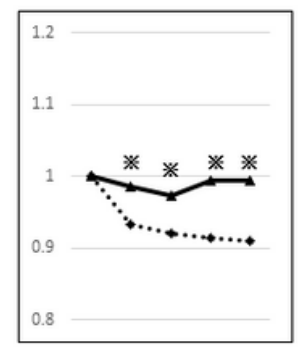

zone6

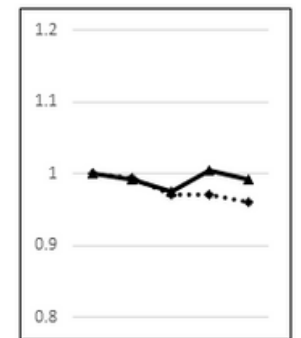

zone3

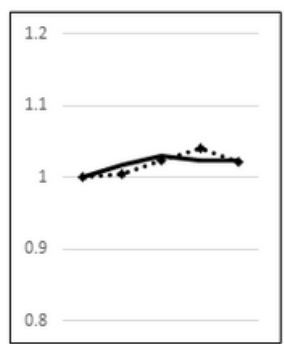

zone7

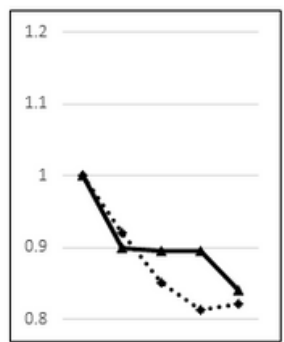

zone4

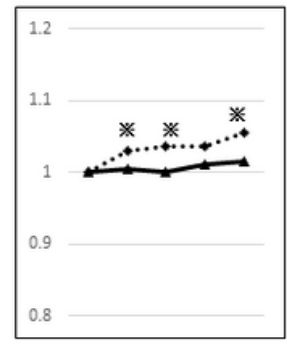

※ $P<0.05$

\section{Figure 3}

BMD changes at $6,12,18$, and 24 months postoperatively in the 7 Gruen zones. Columns represent mean values of BMD changes. The dotted line indicates the value of the HA compaction short stem. The solid line indicates the value of the short tapered-wedge stem. ※ indicates $p<0.05$ compared between two groups. 
Figure 4

\section{(a)}

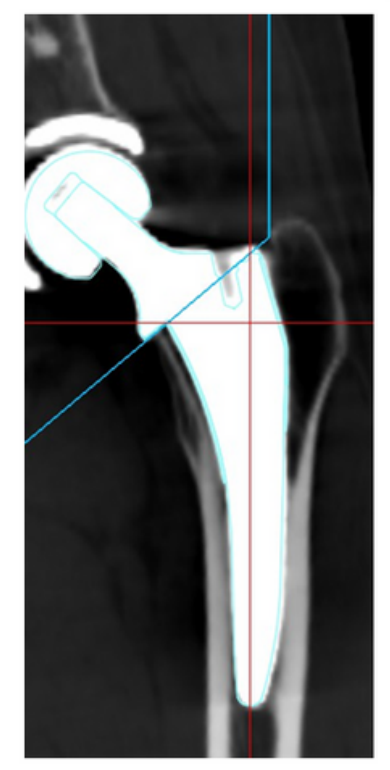

(b)

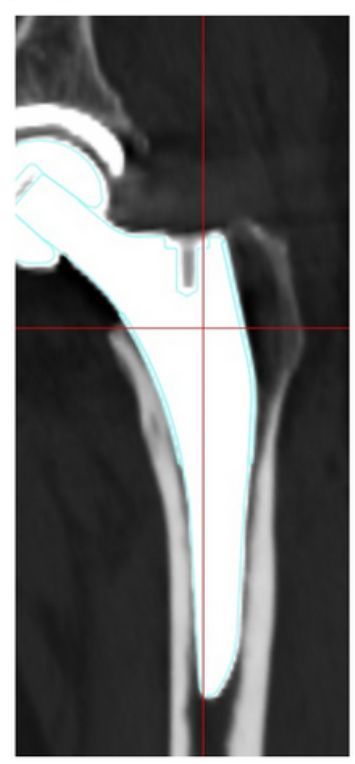

(c)

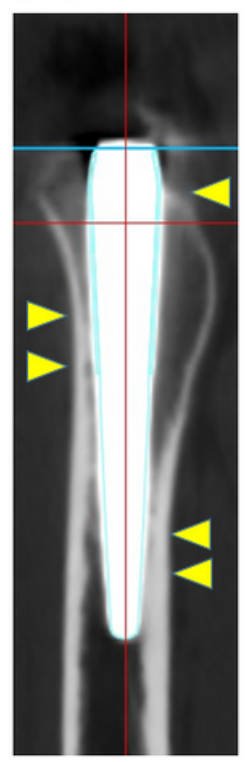

(d)

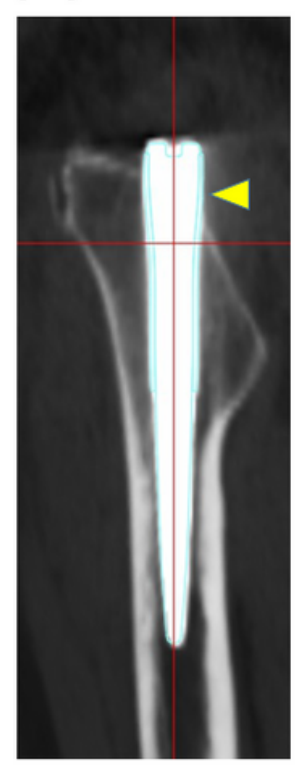

(e)

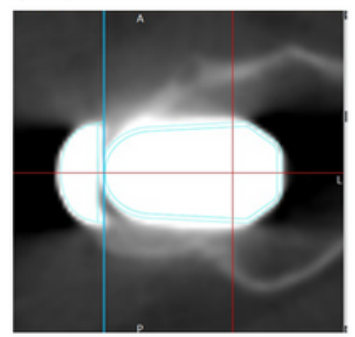

(f)

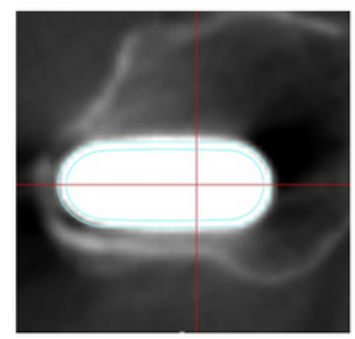

Figure 4

3D reconstruction images of ( $a, c, e)$ the HA compaction short stem (Actis) and (b, $d, f)$ the short tapered-wedge stem (TriLock BPS). (a, b) coronal view (c, d) sagittal view, the yellow triangle indicates contact area of bone and stem (e, f) axial view. 